\title{
Weak Definites
}

\author{
Massimo Poesio \\ University of Edinburgh
}

\section{Introduction}

According to the (neo) Russellian theory of definite descriptions [Russell, 1905; Neale, 1990], a definite description combines an assertion of existence with an assertion of uniqueness. Thus, the sentence John met the student asserts that there is a student, that this student is unique, and John met him/her. These truth conditions can be summarized as in (2).

(1) John met the student.

(2) $\quad(\exists x \operatorname{student}(x) \wedge(\forall y(\operatorname{student}(y) \rightarrow y=x)) \wedge \operatorname{met}(j, x))$

An alternative approach to the semantics of definite descriptions was proposed by Heim in her dissertation [1982]. In Heim's theory, definite and indefinite NPs are semantically equivalent, and both introduce free variables. The truth conditions proposed by Heim for (1) are as follows, where $x$ is a variable.

$$
\operatorname{student}(x) \wedge \operatorname{met}(j, x)
$$

Heim proposes that the difference between definites and indefinites is that (i) definites must be familiar in the context, and (ii) the restriction on a definite NP (the predicate student $(x)$ in (3)) must be presupposed. These aspects of the meaning of definites and indefinites are captured by making reference to the notion of common ground, that Heim proposes to conceptualize in terms of the metaphor of file cards. Each indefinite NP in a discourse introducing the free variable $x$ is conceptualized as adding a new card with index $x$ to a file card set $F$ that represents the common ground, and is augmented as the discourse proceeds. The difference between definites and indefinites is formulated in terms of file card indices, as specified by the following Novelty/Familiarity Condition ([Heim, 1982], p. 370):

\section{Novelty-Familiarity-Condition:}

For $\Phi$ to be felicitous w.r.t. a file $\mathrm{F}$ it is required for every $\mathrm{NP}_{x}$ in $\Phi$ that:

i. if $\mathrm{NP}_{x}$ is [-definite], then $x \notin \operatorname{Dom}(\mathrm{F})$;

ii. if $\mathrm{NP}_{x}$ is [+definite], then

$$
\begin{aligned}
& \text { a. } x \in \operatorname{Dom}(\mathrm{F}) \text {, and } \\
& \text { b. if } \mathrm{NP}_{x} \text { is a formula, } \mathrm{F} \text { entails } \mathrm{NP}_{x} \text {. }
\end{aligned}
$$

Heim argues that the fact that definite descriptions typically refer uniquely is not an intrinsic semantic property, but a consequence of the fact that the listener, upon hearing a definite NP, has to identify a unique index for it among the file cards, which cannot be done unless there is only one 'appropriate' file card. 
In this paper I examine a class of definite descriptions that I will call weak definites. One of my goals in doing so is to gain new insights concerning the conflict between the two semantic theories of definite descriptions just discussed. The data I will examine are exemplified by the sentences in (4).

a. John got these data from the student of a linguist.

b. The village is located on the side of a mountain.

c. I usually had breakfast at the corner of a major intersection.

Definite descriptions of the form [NP The $\overline{\mathrm{N}}$ of NP[-definite] like the student of $a$ linguist in (4a) are fairly common: (4b)-(4c) are not made up, but were found in existing texts. What's interesting about definites of this form is that they have a reading that is not predicted by either the Russellian theory of definite descriptions or Heim's theory. The reading of (4a) I am interested in can be paraphrased as: there is a linguist, and there is a student of that linguist, such that John got the data from that student. This reading can be tentatively characterized by the following expression.

$$
(\exists y \text { linguist }(y) \wedge(\exists x \text { student-of }(x, y) \wedge \operatorname{got}(j, d, x)))
$$

Interpreting (4a) requires no familiarity with the student in question, either in the dictionary sense of familiarity or in Heim's technical sense. The examples could therefore be considered a counterexample to Heim's proposal. On the other hand, the truth conditions of (4a) under this interpretation are not immediately explainable under a Russellian account. Furthermore, although there are several ways in which one may try to capture the interpretation in (5) within a Russellian framework, none of them works very well. Clearly, (4a) does not require the universe of interpretation to include a single individual that can be characterized as the student of a linguist. One might try to rescue the Russellian proposal by taking (4a) to be a case of domain selection, adopting the suggestions of, e.g., Lewis [Lewis, 1979] and Kadmon [1987]. One might claim, that is, that (4a) should be interpreted as The unique SALIENT student of a linguist gave John these data. Let me just remark, for the moment, that this proposal fails to characterize the distinction between the definite in (4a) and the definites in (6), all of which do seem to require a student to be particularly salient in order to be felicitous. I will return to this way of rescuing the Russellian approach later on.
a. John got these data from the student.
b. John got these data from the student who studies with a linguist.
c. John got these data from the student with a brown jacket.

Another way of reconciling the examples in (4) with the Russellian treatment of definites would be to propose that the reading of the student of a linguist in (5) is a case of inverse linking in the sense of May [1985], i.e., that the indefinite NP takes wide scope over the definite. This would enable us to maintain the translation of the definite a quantifier entailing uniqueness However, (4b) and (4c) clearly 
indicate that this proposal is not correct: otherwise, (4c) could never be true, since major intersections typically have four corners.

The class of definites in (4) are interesting not only because they represent a difficulty for the two major theories of definite descriptions, but also because they call into discussion certain generalizations about there-sentences [Milsark, 1977; Barwise and Cooper, 1981; Reuland and ter Meulen, 1987]. These hypotheses are motivated by the contrast in (7).

a. There is a student in the garden.

b. *There is $\{\mathrm{him} / \mathrm{John} /$ the student/every student $\}$ in the garden.

These examples have been taken to indicate that indefinite NPs such as a student can occur in postverbal position in there-sentences, whereas pronouns, proper names, definites and quantified NPs such as every student cannot. This generalization is usually called the Definiteness Restriction [Reuland and ter Meulen, 1987]. Milsark introduced the terms strong NP to refer to NPs that cannot occur in postverbal position, and weak NPs to refer to NPs that can occur in that position.

Definite descriptions are typically classified as strong NPs, on the basis of (7b); consider however (8).

(8) (?)There is the student of a linguist in the garden.

Most of my informants find (8a) acceptable or, at least, much better than any of the sentences in (7b). This suggests that definite descriptions such as the student of a linguist should be classified as weak NPs: hence, the name weak definites for the definite descriptions in this class .

\section{First Hypothesis, Some Assumptions}

Only definites of the form [NP1 the N1 of [NP2 D N2]], where NP2 is indefinite, have the interpretation I discussed above. None of the definites in (6) (repeated below) does. ${ }^{1}$
a. John got these data from the student.
b. John got these data from the student who studies with a linguist.
c. John got these data from the student with a brown jacket.

One might perhaps try to account for the contrast between the examples in (4) and the examples in (6) by hypothesizing that definites are ambiguous between an 'existential' and a 'classical' (i.e., Russellian) reading. This hypothesis runs into problems pretty quickly, however. Weak definites are not simply 'existentials in disguise'. (9a) (below) cannot be paraphrased as (9b), that is not fully grammatical. And anyway, (9c) is not the preferred paraphrase of (9a): the appropriate paraphrase is (9d). The weak definite the student of any linguist in (9a), in other words, has the same force of the free-choice any binding linguist. The same argument applies, mutatis mutandis, to (9e), an example of negative polarity any. ${ }^{2}$ (I owe both these examples and their analysis to Roberto Zamparelli, p.c.) 
a. The student of any linguist should be able to solve this!

b. ?? A student of any linguist should be able to solve this!

c. For any linguist, at least one of his students should be able to solve this.

d. Take any linguist, and any student of that linguist; that student should be able to solve this.

e. I don't think that the student of any linguist could solve this.

In order to accomodate the preferred reading of that sentence, one would have to claim that definites are three ways ambiguous: besides a 'classical' and an 'existential' reading, they also have a 'free-choice' reading, and possibly also a 'negative polarity' reading (although that reading could be equivalent to the 'existential' one). Furthermore, examples like (10) indicate that weak definites have the force of the complement indefinite not only when the indefinite has existential force, but also when it gets bound by an unselective operator and acquires universal force:

(10) If the student of a linguist owns a donkey, he beats it.

A different solution comes to mind, namely, that the reason why weak definites have the interpretation we are interested in is because their interpretation gets 'anchored' to that of the NP that serves as complement of of, so that if that NP gets bound by an operator, these definites get bound by that operator as well. When combined with a treatment of definites and indefinites along the lines of Heim's proposal, this hypothesis would explain the different strength of the weak definites in (4) and in (10). Combined with a story about any similar to that proposed by Kadmon and Landman [1993], according to which any-NPs are essentially indefinites with additional semantic semantic/pragmatic characteristics, this hypothesis would also explain the variation in semantic force between the weak definite the student of a linguist and the weak definite the student of any linguist, as well as the different readings acquired by the latter when the complement NP any linguist is interpreted as free choice or as polarity sensitive.

This 'anchoring' process has two crucial properties. First of all, it occurs only when the definite NP is modified by an of-clause; none of the definites in (6) has the 'weak' interpretation. Secondly, this 'anchoring' results in a weak definite only when the complement itself is a weak NP; when the complement NP is strong, as in the king of France or the student of Chomsky, the definite is also strong. The reading we are interested in is in fact not available when the complement of of is a strong NP, as shown by the fact that the definites in (11) are all required to be familiar, and by the fact that in none of the variants of (8) in (12) is grammatical:

a. John got these data from the student of every linguist.

b. John got these data from the student of Chomsky.

*There is the student of $\{$ Chomsky/every linguist/the linguist $\}$ in the garden. 
In other words, it looks like the 'strength' of the definite depends on what it gets 'anchored' to.

This suggests that the 'strength' of definites may not be an intrinsic (syntactic or semantic) feature. In fact, I' $m$ going to suggest that the aspect of a definite's interpretation that makes it 'strong' may get 'canceled' in certain circumstances before this 'strength' is tested; weak definites, in other words, satisfy the Definiteness Restriction because their strength has been 'canceled'. This 'canceling' is the result of their value being made dependent on the value of the complement NP in the of-clause; other forms of nominal modification do not result in such a dependency being established, and the canceling only takes place if the complement is not itself 'strong'.

In order to make the comparison of the proposed treatment of definiteness and the Definite Restriction as close as possible to related proposals such as Heim's and [Barker, 1991], I will adopt here the same theoretical framework. In particular, I will assume that the interface between syntax and semantics is a level of representation called Logical Form (LF) which results by the application of Quantifier Raising to s-structure, and that the Definiteness Restriction is a constraint on this level of representation. ${ }^{3}$

\section{Strong NPs, Contextual Dependency, and Para- meters}

De Jong [1987] and, more recently, Zucchi [1993] have argued that the key property distinguishing an NP that can occur in there-sentences from an NPs that cannot is presuppositionality. De Jong observes ([1987], p. 276) that the class of NPs that cannot occur in there-sentences coincides with the class of NPs that have a partial interpretation; thus, a quantified NP that has a denotation only in models in which the denotation of the noun is not the empty set cannot occur in there-sentences. Zucchi [1993] proposes the following (and equivalent) condition (p.14):

Presuppositional Characterization of Strong NPs NPs barred from postverbal position of there-sentences, unlike NPs allowed in this position, presuppose that the set denoted by $\overline{\mathrm{N}}$ is nonempty.

As shown by de Jong and Zucchi, the presuppositional characterization of strong NPs correctly identifies the NPs in (7a) as weak, and all the NPs in (7b) as strong. I will not discuss here the reason why the presuppositionality of an NP should affect its ability to occur in postverbal position in these sentences; both issues are discussed in some detail in [Zucchi, 1993]. What's interesting in this characterization of what it means for an NP to be strong, for my purposes, is that it suggests that the 'cancellation' of the 'strength' of an NP discussed in the previous section may turn out to be a case of presupposition cancellation [Gazdar, 1979; Heim, 1983]. 
If we assume with Heim [1987] that LF is the level at which the Definiteness Restriction is checked, then the presuppositional (or non-presuppositional) nature of an NP should be captured by its LF representation. Heim [1983] argued that a sentence's presuppositions are essentially constraints imposed by that sentence on the contexts in which it may occur. Thus, Heim's definition of presupposition ([Heim, 1983], p. 117) is as follows:

$$
S \text { presupposes } \mathrm{p} \text { iff all contexts that admit } \mathrm{S} \text { entail } \mathrm{p} \text {. }
$$

Van der Sandt [1990], building on Heim's account, argues that talking of 'presupposition cancellation' is miguided, and that 'cancellation' really is nothing else but a case of anaphora. For example, the reason why (14) does not presuppose the existence of a king of France is because the antecedent of the conditional modifies the context in which the consequent is evaluated creating a context that entails the existence of a king of France, thus satisfying the definition in (13):

(14) If there is a king of France, the king of France is bald.

This suggests that the presuppositional nature of an NP is represented at LF in the same way that other forms of context-dependency are. In a lot of recent work 'contextual variables' have been used as a way to represent context dependency. Such variables have been used by Rooth in [1992] to restrict the set of properties that focus-sensitive particles quantify over, and by Hinrichs [1988] to capture domain selection. As well, the idea of having context-dependent variables as part of the interpretation of a sentence is closely related to the idea developed in Situation Semantics that the meaning of a sentence may contain parameters. In Situation Semantics, a parameter represents a 'hole' to be filled by context. The notion of parameter was proposed in [Barwise and Perry, 1983] and extensively used by Gawron and Peters [1990] to specify the meaning of quantifiers and anaphoric expressions.

I propose, first of all, that constituents indicating that the interpretation of a lexical item is context-dependent occur at LF; I will adopt Situation Semantics' terminology and call these LF constituents parameters. The effect of parameters is to make an LF subject to the following felicity condition:

Condition on Parametric LFs In order for the interpretation of a sentence specified by Logical Form $l$ to be felicitous, context must provide values of the appropriate type for all the parameters occurring in $l$. i.e., if $X_{1}, \ldots, X_{n}$ are the parameters in $l$ (I use capital letters to indicate parameters throughout), a value can only be assigned to $l$ relative to an assignment of values $y_{1}, \ldots$, $y_{n}$ to the parameters of $l$, where $y_{1}, \ldots, y_{n}$ are indices of file cards.

Next, I propose to implement de Jong's and Zucchi's hypothesis about the connection between strong NPs and presuppositionality by defining a strong NP as an NP whose LF representation contains one or more parameters. The Definiteness Restriction becomes then a restriction on the occurrence of parameters at LF: 


\section{Definiteness Restriction : *[There V[+be] NP[X] $\{\mathrm{PP}\}]$}

The meaning of this definition is as follows: an LF configuration of the form [There V $[+b e] N P[X]\{P P\}]$, where NP[X] is an NP whose interpretation depends on the value of the parameter $\mathrm{X}$, is ungrammatical.

Let me explain now how the occurrence of parameters at LF characterizes the presuppositional aspects of the interpretation of a strong NP. Pronouns are the prototypical context-dependent NP, and they are also very clearly strong NPs, as shown by the clear ungrammaticality of sentences such as *There is him in the garden. I propose that pronouns are 'essentially context dependent,' in the sense that their LF representation consists of just a parameter. For example, he translates as $X$, where $X$ is a parameter, and *There is him in the garden. has the folowing LF representation:

\section{(15) [There is $X$ in the garden]}

(I am leaving the specification of the translation of the definite for later). (15) is ruled ungrammatical by the Definiteness Restriction presented above.

The presuppositional aspect of the interpretation of strong quantifiers is their domain of quantification, i.e., the set of objects that are chosen to evaluate the truth of a quantified assertion. It is well-known that sentence (16) can be truthfully used to describe a situation in which only a contextually determined subset of the set of all individuals (say, all the individuals in a particular room) was asleep, whereas others-for example, the speaker-were awake [Partee, 1991].

(16) Everybody was asleep.

There are several ways one could use parameters to represent the fact that the domain of quantification has to be identified. The question one has to consider is, what is it that the context has to provide in order for a listener to be able to interpret a sentence such as (16)? One hypothesis that immediately comes to mind is that what has to be identified in interpreting (16) is a set of people, i.e., that the LF for (16) includes either a parameter $X$ that stands for the subset of persons to be quantified over, as in (17a), or, equivalently, a parameter $C$ that indicates that what has to be identified is a property, as in (17b).

$$
\begin{array}{ll}
\text { a. } & {[[\operatorname{every} x \operatorname{person}(x) \wedge x \in X][\operatorname{asleep}(x)]]} \\
\text { b. } & {[[\operatorname{every} x \operatorname{person}(x) \wedge C(X)][\operatorname{asleep}(x)]]}
\end{array}
$$

An alternative-and, I will argue, more fruitful-way of thinking about what goes on in domain restriction is suggested by Enç's treatment of tense and NPs in [Enç, 1986]. Enç observes that treatments of tense based either on Priorean operators (as in Montague Grammar) or on existential quantification over times (as in Dowty's system [1979]) fail to capture all of the readings of sentences such as (18). There is no way, for example, to capture the reading according to which for all past, present, or future rich men there is a point in their past at which they were obnoxious children. 
Enç argues that the only way to generate all the readings of sentences like (18) is to have one 'tense operator' for each NP, in addition to the tense operator associated with the verb. She also notices, however, that the 'tense operators' associated with NPs should always take narrow scope. In (19), for example, although we want a past operator for every hostage, since these individuals may have been hostages in the past, we do not want that operator to take scope over the verb, since the sentence does not have a reading in which the meeting occurred at some time in the past.

(19) John will meet every hostage at the president's party.

Enç concludes that what we need is to associate a temporal interval with each predicate, whose value is fixed by context; this temporal interval specifies the time at which the predicate has to be evaluated.

Enç's proposal has been adopted in Situation Theory (see especially [Gawron and Peters, 1990; Cooper, 1993]), where, however, each predicate is indexed with a situation rather than with a time interval, as in $\operatorname{asleep}_{s}(x)$. A variant of this notation is also used by Heim in [1990]. But if we assume that each predicate has this extra argument, we can also use it indicate the domain of quantification: in (16), for example, the set of individuals that are asleep is the set of individuals contained in the particular situation that the speaker has in mind. According to this 'situational' way of representing domain selection, the task of the listener upon hearing a strong quantified NP is not to select a set, but select a situation. Since this situation has to be identified, the representation of the head noun at Logical Form will contain a parameter as its situational index. This results in the following LF representation for (16):

$$
\text { [[every } \left.\left.x \operatorname{person}_{S}(x)\right]\left[\operatorname{asleep}_{s}(x)\right]\right]
$$

If we generalize the notion of 'strong LF constituent' to include not only a constituent whose representation includes a parameter, but more in general any constituent whose interpretation depends on the value of a parameter, such as a variable left in place by Quantifier Raising, we correctly predict that $\mathrm{LF}$ configurations such as (21), the LF analysis of There is every student in the garden, are ruled out. ${ }^{4}$

$$
\text { [[every } \left.x \text { student }_{S}(x)\right] \text { [there } x \text { in-the-garden]] }
$$

The difference between strong quantified NPs and the non-presuppositional reading of weak NPs, in de Jong and Zucchi's analysis, is that the former presuppose the existence of a set, whereas the latter assert that existence; in other words, only strong quantified NPs require a domain restriction. I propose that this difference is captured at LF in this way: the representation of strong quantified NPs differs from that of weak quantified NPs in that the situational argument of the former is a parameter, whereas the situational argument of the latter is a variable that may 
be either existentially bound or may be bound by some unselective operator. The LF representation of the non-specific reading of Someone is asleep is then: ${ }^{5}$

$$
\text { [person }_{s}(x) \wedge \operatorname{asleep}_{s}(x) \text { ] }
$$

An apparently minor, but in fact crucial aspect of the representation in (22) is the assumption that the situational argument of weak NPs in their non-presuppositional reading is the same as the situational argument of the main predicate, asleep. This assumption about the 'non-raised' interpretation of weak NPs was already adopted by Heim [1990]. Heim makes this assumption, without discussing it, when reformulating the DRT semantics for sentences containing adverbs of quantification such as (23).

$$
\text { If a man is from Athens, he (always) likes ouzo. }
$$

In that paper, Heim treats adverbs of quantification such as always are quantifiers over situations (as proposed by, e.g., [de Swart, 1991]) instead of quantifiers over assignments as in [Heim, 1982]. The truth conditions of this sentence are paraphrased by Heim as follows: For every (minimal) situation $\mathbf{s}$ in which there is a man who is from Athens, there is an extended situation $\mathbf{s}^{\prime}$ such that the unique man from Athens in $\mathbf{s}$ likes ouzo in $\mathbf{s}^{\prime}$. The point is that the sentence does not have a reading in which the indefinite is interpreted non-specifically, yet the man is part of a situation and he is from Athens in another situation. In fact, I am going to propose that the absence of this reading reflects a fundamental constraint on interpretation, that can be expressed as the following LF constraint:

Constraint on Situation Identity Let $\left[p_{s}(x) \wedge \ldots \wedge \mathrm{q}_{s^{\prime}}(y)\right]$ be an LF clause, i.e., a conjunction of constituents that have 'the same level of embedding' at LF after Quantifier Raising. Then if $\mathrm{p}_{s}(x)$ and $\mathrm{q}_{s^{\prime}}(y)$ are two conditions in that clause, $s=s^{\prime}$.

According to this constraint, the Logical Form that results by raising all operators must be such that all predicates that 'end up in the same place at LF, as it where, must have the same situational index: i.e., they must all be predicates about the same situation.

Proper names like Chomsky or France are also presuppositional-the proper name Chomsky may only be used felicitously when the context provides an appropriate referent-and strong, as indicated by the ungrammaticality of ??There is Chomsky in the garden. I propose that the LF representation of the proper name Chomsky consists of a parameter $X$, together with the presupposition that the referent of the parameter is called 'Chomsky'; this latter presupposition can be expressed in terms of parameters as a requirement that the context provide a situation $S$ in which $X$ is called 'Chomsky'. ${ }^{6}$ There is Chomsky in the garden thus has the following LF characterization, that is ruled out by the Definiteness Restriction formulated above: 
There is one last aspect of the use of parameters to capture presuppositionality that needs to be discussed before proceeding to the semantics of definite descriptions. Consider the following example:

John thinks that there is a picture of himself in the museum.

Since the reflexive pronoun himself is anaphoric, it should be represented as a parameter. We would the predict that (25) is bad, but in fact it is grammatical. Why is that? Note that the explanation can't simply be structural, since (26) is still bad:

?*There is a picture of him in the museum.

An important property of parameters in Situation Theory is that they can be anchored, i.e., their value can be set equal to some file card index; an anchored parameter can be replaced by its non-parametric value. Clearly, if a parameter gets anchored at LF already, context doesn't need to provide a value for that parameter, which therefore counts as a non-parametric sentence constituent. I am going to propose that the reason why (25) is good is because himself is anchored in the LF representation for (25).

\section{A Parametric Semantics for Definite Descriptions}

According to Heim, the interpretation of a definite like the student imposes two constraints on the context. The context has to (i) provide an index for the definite, and (ii) presuppose that the value assigned to that index satisfies the restriction specified by the head noun, i.e., that that object has the property of being a student.

As far as the first of these constraints is concerned, Heim's theory can be refomulated in terms of parameters by assuming that the LF representation for a definite contains a parameter, as follows:

$$
\text { the student } \sim[\operatorname{student}(D)]
$$

Because of the Condition on Parametric LFs discussed in $\S 3$, having a parameter $D$ in (27) is equivalent to Heim's requirement that the index assigned to the definite has to be that of an existing file card. The condition that context must presuppose that the referent of the definite is a student can be modeled by augmenting the predicate with a situational argument and letting this argument be a parameter $S$, as I proposed to do for other strong NPs in $\S 3:^{7}$

$$
\text { the student } \sim\left[\text { student }_{S}(D)\right]
$$

However, the translation in (28) is not general enough to cover all classes of definites, and in particular, it is not adequate to deal with a class of definites that are both very common and very closely related to weak definites. Heim notices in chapter 3 of her dissertation that while her proposal is appropriate for anaphoric and deictic definites, these are just two of the known ways to use definite 
descriptions. Among the forms of definite descriptions use that are left out is one of the most common uses of definite descriptions, the so-called bridging definites [Clark, 1977] or associative definites [Hawkins, 1978]. This class of definites is illustrated by the examples in (29).

a. We went to a wedding last Sunday. The bride wore red.

b. This year's biggest attempted hostile raid in the U.S., Paramount Communications Inc.'s failed $\$ 10.7$ billion bid for Time Inc., relied solely on bank loans for financing the initial offer.

In (29b), for example, the antecedent for the definite description the initial offer has not been explicitly introduced in the discourse. The use of that definite is felicitous because it is possible for the listener to establish a connection ('bridge') between the definite and the index in the file card set assigned to Paramount Inc.'s hostile takeover attempt.

Heim [1982] suggests that what Clark called 'bridging' is an example of what Lewis called accomodation [Lewis, 1979]: in order to interpret the sentences in (29), something has to be added to ('accomodated into') the context. The problem is how to impose constraints on accomodation so as to avoid incorrect predictions, for consider the sentences in (30):

a. A car passed roaring. The radiator cap was shiny.

b. A car passed roaring. ??The dog was barking.

While (30a) is felicitous-it is easy to establish a connection between the radiator cap and the car- (30b) is infelicitous, even though one can easily concoct some story about the relation between the dog and the car-say, the dog is in the back seat of the car.

An account of the conditions under which bridging reference is possible was given by Barker [Barker, 1991; Barker, 1992]. Barker's analysis is based on a distinction between lexical possessives and extrinsic possessives. Examples of lexical possessives are given in (31); examples of extrinsic possessives are in (32). According to Barker, what distinguishes the possessives in (31) from the possessives in (32) is that all the nouns in (31) have a two-place relation as one of their lexical meanings.

$$
\begin{aligned}
& \text { a. John's child (Kinship relations) } \\
& \text { b. John's nose, the table's top (Part/whole relations) } \\
& \text { a. John's cat } \\
& \text { b. John's truck }
\end{aligned}
$$

Barker proposes that two conditions have to be satisfied in order for bridging references to be felicitous ([Barker, 1991], p. 142-143). First of all, the head noun of the bridging definite must include among its lexical entries a relational meaning. Secondly, this relational meaning must be salient in context. Thus, according to Barker, (30a) is felicitous because the head noun radiator cap may 
have a relational interpretation and this relational interpretation is made salient by the mention of a car, whereas (30b) is infelicitous because the head noun $d o g$ does not have such a relational meaning.

The relevance of associative definites to the topic of this paper is shown by the following variant of (30):
a. A car passed roaring. The radiator cap of the car was shiny.
b. A car passed roaring. ??The dog of the car was barking.

As these examples indicate, there is a connection between the class of definites that give rise to the weak definite interpretation and the cases of bridging reference. Intuitively, the connection is as follows. Both definite NPs of the form the radiator cap of the car and associative definites require the head noun to have a relational interpretation. In the case of weak definites, however, the speaker makes it clear that the relational interpretation of the head noun has to used, whereas in the case of bridging references, the relational interpretation has to be salient enough that the listener may recognize that that indeed is the required interpretation. Thus, in the case of weak definites, the condition on the saliency of the relational interpretation is 'waived'.

Clearly, formulating a semantics for definite descriptions that accounts for the associative use as well is going to be an important part of an account of weak definites. In order to give a uniform treatment both to anaphoric definites (in the larger sense), that denote the same object as a previous file card, and to associative definites, that denote an object that is not the value of an existing index, although it is related to the value of a file card in the current set, it seems necessary to require both definites and indefinites to introduce a new file card. We can then reinterpret the Familiarity Condition as stating that the LF representation of definites must contain a parameter to be equated to an existing index. In the case of a nonrelational definite such as the $d o g$, or of the non-relational interpretation of a definite such as the student, the new index and the parameter must denote the same object:

$$
\text { the student } \sim\left[\operatorname{dog}_{S}(x) \wedge x=D\right]
$$

The difference between (34) and (28) is that a new file card index $x$ is introduced in (34), but $x$ is required to have the same value as an existing file card index $D$; (34) is thus equivalent to (27).

In the case of the relational interpretation of the definite descriptions the student or the radiator cap, however, the file card introduced for the definite does not have the same denotation of the parameter: the LF representation is shown below.

$$
\text { the student } \left.\sim \text { [student }_{S}(x, D)\right]
$$




\section{The Solution: Parameter Anchoring}

My proposal concerning the weak definites puzzle is that the properties of weak definites are due to the fact that in these constructions the head noun receives a relational translation of the kind shown in (35), and because of this, the parameters in the interpretation of the definite get anchored at LF, thus 'canceling' the presupposition much as in the case of John thinks that there is a picture of himself in the museum that I discussed in $\S 3$. The interpretation in which parameters are anchored does not impose on the context the constraint of providing a suitable referent, which explains why no familiarity is required, which in turns eliminates the requirement for uniqueness, if we accept Heim's reduction of uniqueness to familiarity; it also allows the definite NP to pass the Definiteness Restriction test.

The contrast between a definite NP of the form [NP1 the N1 of NP2[-definite]], whose parameters get anchored at LF, and the definites in (6)-for example, a definite NP of the form [NP1 the N1 with NP2[-definite]] - whose parameters are not, is caused, I propose, by the semantic difference between the two complements of NP2[-definite] and with NP2[-definite]. Barker [Barker, 1991] and Jackendoff [Jackendoff, 1977] argue that of-NPs specify an argument of the predicate denoted by the head of the noun phrase, whereas other postnominal modifiers-e.g., other PPs, or relative clauses - specify adjuncts of that predicate. In other words, the LF representation of (4a), shown in (36b), is similar to (35), whereas the LF representation of (6c), shown in (36d), is similar to (34).

a. John got these data from the student of a linguist.

b. $\quad\left[\right.$ linguist $_{s}(x) \wedge \operatorname{student}_{S}(y, x) \wedge \mathrm{John}_{s^{\prime}}(Z) \wedge$ got-from $_{s}(Z$,these-data,y $\left.)\right]$

c. John got these data from the student with a brown jacket.

d. $\quad\left[\operatorname{brown}_{\text {-jacket }}(x) \wedge \operatorname{student}_{s}(y) \wedge y=D \wedge\right.$ with $_{s}(y, x) \wedge \operatorname{John}_{S^{\prime}}(Z) \wedge$ got-from ${ }_{s}(Z$,these-data,y)]

As discussed in $\S 4$, nouns like student have (at least) two lexical entries, according to Barker: one of the entries is the two place relation student $s(y, x)$, the other the property student $s(y)$. The selection of one or the other interpretation is left to the context in case of associative descriptions, hence the necessity for the 'relational' interpretation to be salient. In the case of NPs whose head noun has an of-clause as a complement, the relational interpretation is preferred (as in (36b)); other complements instead suggest that the other interpretation has to be used (as in in (36d)). The crucial importance of the fact that the complement NP serves as argument for the relational noun receives further confirmation by the examination of NPs that although of the form [NP1 the N1 of NP2[-definite]] are nevertheless infelicitous as weak definites:

(37) a. ??I found this money behind the brick of a wall.

b. ??I don't want to steal the book of a library.

Neither brick in (37a) and book in (37b) can be interpreted as relational, hence the definites are infelicitous. 
The important difference between (36b) and (36d) is that (36d) still contains a parameter $D$ indicating that the antecedent has to be identified, whereas the connection between the referent of the definite and the context is already established in (36b): the parameter $D$ in (35) is anchored to the index $x$ of the second argument of the relational noun. To put this otherwise, the sentence itself asserts the existence of a value for $D$ in the context, namely, $x$; by equating $D$ to $x$ at LF, the presupposition has been 'canceled'.

The presupposition only gets 'canceled,' however, when the second argument of the relation is not itself a parameter, or a variable whose value depends on the value of a parameter, as in the student of Chomsky or the student of every linguist. Consider the LF translations of the sentences John got these data from the student of Chomsky and John got these data from the student of every linguist:

a. John got these data from the student of Chomsky.

b. $\quad\left[\operatorname{John}_{S}(Z) \wedge\right.$ student $_{S^{\prime}}(y, X) \wedge$ Chomsky $_{S^{\prime \prime}}(X) \wedge$ got-from $_{s}(Z$,thesedata,y)]

c. John got these data from the student of every linguist.

d. [[every $x$ linguist $\left._{S}(x)\right]\left[\mathrm{John}_{S^{\prime}}(Z) \wedge\right.$ student $_{S^{\prime \prime}}(y, x) \wedge$ got-from $_{s}($ $Z$,these-data,y)]]

In (38b), the second argument of the relation student ${ }_{s^{\prime}}(y, X)$ is the parameter $X$, therefore the LF representation of the definite is still presuppositional. In (38b), the second argument is the variable $x$, that is bound by the raised quantifier [every $x$ linguist $_{S}(x)$ ] whose value depends on the value of the parameter $S$, and therefore again the LF representation of the definite is presuppositional.

This last assertion will certainly result in the objection that if [every $x$ linguist $\left._{S}(x)\right]$ counts as presuppositional because of $S$, then surely student ${ }_{S}(y, x)$ in (36b) should count as presuppositional as well. This is correct; however, we can now exploit the constraint on LF that I called Constraint on Situation Identity in $\S 3$. According to this constraint, motivated by facts about adverbs of quantification, all predicates that remain in the same position at LF after Quantifier Raising must be describing the same situation, i.e., all of their situational indices must be the same. If we enforce this constraint on (36b) we get the Logical Form in (39a), which is equivalent to the Logical Form in (39b); this should be compared with the LF representation for John got these dat a from the student of Chomsky, whose representation is shown in (39c). Notice that the representation of the definite comes out 'parameterless' in (39b), but presuppositional in (39c).

$$
\begin{array}{ll}
\text { a. } & {\left[\operatorname{John}_{S^{\prime}}(Z) \wedge \text { student }_{s}(y, x) \wedge \text { linguist }_{s}(x) \wedge S=s \wedge S^{\prime}=s \wedge \text { got-from }_{s}(\right.} \\
& Z, \text { these-data,y })] \\
\text { b. } & {\left[\operatorname{John}_{s}(Z) \wedge \text { student }_{s}(y, x) \wedge \text { linguist }_{s}(x) \wedge \text { got-from }_{s}(Z \text {,these-data,y })\right]} \\
\text { c. } & {\left[\operatorname{John}_{s}(Z) \wedge \text { student }_{s}(y, X) \wedge \text { Chomsky }_{s}(X) \wedge \text { got-from }_{s}(Z \text {,these- }\right.} \\
& \text { data,y })]
\end{array}
$$

At this point, it should also be clear why the force of weak definites depends on the force of their arguments. By assigning to the student of a linguist the translation in 
(39b), the theory I have presented predicts that an unselective operator binding the variable $x$ introduced by the complement NP $a$ linguist will necessarily bind the variable $y$ introduced by the definite. If we assume with Kadmon and Landman that any-NPs are like indefinites, and therefore presumably are assigned their quantificational force by an unselective operator, we also predict that the definite the student of any linguist will be bound by whatever operator binds the NP any linguist, which explains the facts in (9).

\section{Acknowledgments}

This work has been done in collaboration with Roberto Zamparelli, who came up with most of the examples and helped me considerably in arriving at an analysis, but in the end generously declined to appear as an author. I would also like to thank Chris Barker, whose dissertation helped us a lot and who participated in many of our discussions. Thanks to James Allen, Robin Cooper, Jonathan Ginzburg, Janet Hitzeman, Helen de Hoop, Manfred Krifka, Louise McNally and David Milward for valuable suggestions and comments. The work here described has been funded in part by the LRE contract 62-0151.

\section{Notes}

${ }^{1}$ There is one class of NPs that behave like weak definites, and these are possessive descriptions [Barker, 1991] of the form [NP1 [NP2 D N2]'s N1], where NP2 is indefinite. These NPs have no familiarity/uniqueness presuppositions, as shown in (40), and are not subject to the Definiteness Restriction, as shown in (41).

(40) John got these data from a linguist's student.

(41) There is a linguist's student in the garden.

Although in principle it should be possible to extend the treatment discussed below to possessive descriptions, some problems are still open.

${ }^{2}$ These examples represent a further problem for the Russellian approach: even if domain selection could be invoked for sentences like (4a), it's not at all clear how the preferred reading of (9a) could be obtained.

${ }^{3} \mathrm{My}$ proposal can be formulated in a purely model-theoretical fashion, but this would require introducing a considerable amount of material unrelated to the main topic of this paper. A treatment of this type is presented in [Poesio, 1994]. 
${ }^{4}$ The hypothesis that what determines the acceptability of a sentence like (21) is not the occurrence of a variable in post-verbal position, but the status of the raised NP, is supported by the contrast reported by Heim [1987] between the acceptability of (42a), in which the variable that presumably translates the trace is bound by the weak NP how many, and the unacceptability of (42b), in which the variable is bound by the strong NP which one of the two men.

a. How many soldiers were there in the infirmary?

b. ??Which one of the two men was there in the infirmary?

${ }^{5}$ The presuppositional interpretation of a weak NP-for example, the specific reading of an indefinite NP-results instead in a parametric LF, which is strong. One can think of this proposal as an alternative to Enç's [1991], where instead of having two indices per NP, one has an LF constituent denoting the referent of the $\mathrm{NP}$ and an LF constituent denoting the situation of which that referent is a part.

${ }^{6}$ This translation is neutral with respect to the question of whether proper names are to be interpreted attributively or referentially. The interpretation depends on the value specified for $X$; thus, one can force a referential interpretation by requiring the value of $X$ to be a constant.

${ }^{7}$ Reformulated in this way, Heim's theory becomes very similar to Hawkins' 'location theory' of definite descriptions, according to which the task of the listener upon hearing a definite description is to (i) identify the situation of which the referent is a part, and (ii) identify the referent of the definite within that situation [Hawkins, 1978].

\section{References}

[Barker, 1991] Barker, C. 1991. Possessive Descriptions. Ph.D. Dissertation, University of California at Santa Cruz, Santa Cruz, CA.

[Barker, 1992] Barker, C. 1992. Definite possessives and discourse novelty. In Proc. of CLS-92.

[Barwise and Cooper, 1981] Barwise, J. and Cooper, R. 1981. Generalized quantifiers and natural language. Linguistics and Philosophy 4(2):159-219.

[Barwise and Perry, 1983] Barwise, J. and Perry, J. 1983. Situations and Attitudes. The MIT Press.

[Clark, 1977] Clark, H. H. 1977. Bridging. In Johnson-Laird, P. N. and Wason, P.C., editors 1977, Thinking: Readings in Cognitive Science. Cambridge University Press, London and New York. 
[Cooper, 1993] Cooper, R. 1993. Generalised quantifiers and resource situations. In Aczel, P.; Israel, D.; Katagiri, Y.; and Peters, S., editors 1993, Situation Theory and its Applications, v.3. CSLI and University of Chicago, Stanford. chapter 8, 191-212.

[de Jong, 1987] Jong, F.de 1987. The compositional nature of (in)definiteness. In Reuland, E. J. and Meulen, A. G. B.ter, editors 1987, The Representation of (In)definiteness. The MIT Press, Cambridge, MA. chapter 11, 270-285.

[de Swart, 1991] Swart, H.de 1991. Adverbs of quantification : a generalized quantifier approach. Ph.D. Dissertation, Rijksuniversiteit Groningen.

[Dowty, 1979] Dowty, D. R. 1979. Word Meaning and Montague Grammar. D. Reidel, Dordrecht, Holland.

[Enç, 1986] Enç, M. 1986. Towards a referential analysis of temporal expressions. Linguistics and Philosophy 9(4):405-426.

[Enç, 1991] Enç, M. 1991. The semantics of specificity. Linguistic Inquiry 22(1):1-25.

[Gawron and Peters, 1990] Gawron, J. M. and Peters, S. 1990. Anaphora and Quantification in Situation Semantics, volume 19 of Lecture Notes. CSLI.

[Gazdar, 1979] Gazdar, G. 1979. Pragmatics. Academic Press, New York.

[Hawkins, 1978] Hawkins, J. A. 1978. Definiteness and Indefiniteness. Croom Helm, London.

[Heim, 1982] Heim, I. 1982. The Semantics of Definite and Indefinite Noun Phrases. Ph.D. Dissertation, University of Massachusetts at Amherst.

[Heim, 1983] Heim, I. 1983. On the projection problem for presuppositions. In Proc. WCFFL II, Stanford, CA.

[Heim, 1987] Heim, I. 1987. Where does the definiteness restriction apply? In Meulen, A.ter and Reuland, E., editors 1987, The Representation of (In)definitess. MIT Press.

[Heim, 1990] Heim, I. 1990. E-type pronouns and donkey anaphora. Linguistics and Philosophy 13(2):137-138.

[Hinrichs, 1988] Hinrichs, E. 1988. Tense, quantifiers, and contexts. Computational Linguistics 14(2):3-14.

[Jackendoff, 1977] Jackendoff, R. 1977. $\bar{X}$-bar Syntax. The MIT Press, Cambridge, MA. 
[Kadmon and Landman, 1993] Kadmon, N. and Landman, F. 1993. Any. Linguistics and Philosophy 16(4):353-422.

[Kadmon, 1987] Kadmon, N. 1987. On Unique and Non-Unique Reference and Asymmetric Quantification. Ph.D. Dissertation, University of Massachusetts at Amherst.

[Lewis, 1979] Lewis, D. K. 1979. Scorekeeping in a language game. Journal of Philosophical Logic 8:339-359.

[May, 1985] May, R. 1985. Logical Form in Natural Language. The MIT Press.

[Milsark, 1977] Milsark, G. 1977. Towards an explanation of certain peculiarities in the existential construction in english. Linguistic Analysis 3:1-30.

[Neale, 1990] Neale, S. 1990. Descriptions. The MIT Press, Cambridge, MA.

[Partee, 1991] Partee, B. H. 1991. Topic, focus and quantification. In Proc. SALT-91.

[Poesio, 1994] Poesio, M. 1994. Discourse Interpretation and the Scope of Operators. Ph.D. Dissertation, University of Rochester, Department of Computer Science, Rochester, NY.

[Reuland and ter Meulen, 1987] Reuland, E. J. and Meulen, A. G. B.ter, editors 1987. The Representation of (In)definiteness. The MIT Press, Cambridge, MA.

[Rooth, 1992] Rooth, M. 1992. A theory of focus interpretation. Natural Language Semantics 1:75-116.

[Russell, 1905] Russell, B. 1905. On denoting. Mind 14:479-493. Reprinted in Logic and Knowledge, ed. R. C. Marsh. London: George Allen and Unwin.

[van der Sandt, 1990] Sandt, R. A.van der 1990. Anaphora and accomodation. Workshop on Quantification and Anaphora, Second European Summer School in Language, Logic and Information.

[Zucchi, 1993] Zucchi, A. 1993. The ingredients of definiteness and the definiteness effect. Natural Language Semantics. To appear. 